\title{
Investigating the Functional Role of Sidewalks in Promoting Social Interactions (Case Study: Aminolmolk Street in Tehran)
}

\author{
SiminGhadami \\ Master of Urban Design, Urban Engineering, Hamedan Branch, Islamic azad university science and research, \\ hamedan,iran
}

\begin{abstract}
One of the innate human needs is the need to establish social relationships and interactions, such that human cannot live without meeting this basic need. Sidewalks are a place for the presence of all citizens, such that people in these places have interactive relationships with each other and experience collective life. However, in our country still enough attention is not seriously paid to designing of sidewalks and their being responsive in meeting human needs. The purpose of the present study was to investigate the functional role of sidewalks in promoting social interactions. The case study wasAminolmolk Street in Tehran's Imamzadeh Hasan (PBUH) neighborhood. The research method was descriptive-analytical and applied, and data collection tool included a researcher-made questionnaire. Sample size based on Morgan table was 384 and sampling method was simple random sampling. The statistical population of the study included residents of the mentioned neighborhood. SPSS and Lisrel software programs have been used to analyze the data. The results showed that sidewalks had a significant social and economic impact on the promotion of social interactions; but this impact was not confirmed in terms of environmental and physical aspects. Therefore, Imamzadeh Hasan (PBUH) neighborhood, focusing on Aminolmolk Street, was active in terms of social and economic functions, and the old and worn out texture (poor environmental and physical functions) did not affect the amount of social relationships.
\end{abstract}

Keywords:Sidewalk, Social interactions, Imamzadeh Hasan (PBUH) neighborhood, Aminolmolk Street

\section{Introduction and statement of the problem}

Urban space reflects socio-cultural relations in the city, and at the same time finds its "identity" based on these relationships. Urban space as a built environment can facilitate or inhibit social relationships and affect them and, in turn, be affected by them (Rapport, 1977: 2). Some part of human actions and activities occur in space, and according to Anthony Giddens, "space is a physical body for social interactions" (Giddens, 1990: 243). Urban space is as a physical structure for social interactions that is accessible for members of urban community. In contemporary cities, the construction of public spaces for traffic of vehicles has become a priority compared to the creation of spaces for socio-cultural contacts and relationships and, even in some cases, has caused the loss of traditional urban spaces with aesthetic values and important socio-cultural functions (Trancik, 1986). Sidewalks are a place for the presence of all citizens and their participation in collective life and they act in the scale of the whole city. In an interactive relationship with each other, citizens experience being with each other in these open urban spaces and try to promote collective life. This is why sidewalks are considered as the most important urban public spaces that are the place for social interactions. The importance and status of sidewalks' landscape for creating an appropriate ground for the establishment of healthy social interactions among citizens is thus identified. Therefore, attempts have been done to, recognize the needs of the present modern society and its users considering the values existing in those spaces, designing and constructing a sociable and participatory space that in addition to being a place for social exchanges, inspires the sense of place and belonging to the individual. And since different activities and actions change easily according to the needs of time, designing sidewalks should have the required flexibility. Diversity of experience of space implies environmental characteristics of places that have diverse forms, uses and meanings; attractive diverse uses, by providing and producing flows of pedestrians' movement in sidewalk space, provide this quality (Bentley et al., 2003).

On the other hand, gradual dominance of movement of vehicles in urban spaces and streets has made urban planning and design far from the scales and needs of pedestrians and thus, has reduced the social and cultural values and attractions of urban spaces. Continuity of such a process has placed civil life of urban spaces and civilization at risk (Karimi and NeginTaji, 2012: 7). This is while walking is the most natural, old and necessary form of human movement and it is still the most important opportunity to observe places, activities and feelings of passion and mobility of life and to discover the values and attractions that lie in the environment.It has fundamental importance in perceiving spatial identity, the sense of belonging to the environment and receiving environmental qualities (Rasouli and RahimdokhtKhorram, 2009: 103). Therefore, the importance and attention 
to pedestrians and making the urban environment suitable for their presence in urban spaces is one of the challenges facing our today's metropolises. The necessity of this issue is more clearly understood given that it has been neglected in our country and especially in urban planning studies (Abbaszadeh and Tamri, 2012: 1).

Aminolmolk Street, located in Imamzadeh Hasan (PBUH) neighborhood, with an old texture, has a great deal of crowding in different times of year and provides the ground for the establishment of social communications between citizens, such that it can be said that this neighborhood and the mentioned street have a trans-regional function. In this regard, the present study sought to examine the functional role of sidewalks in social, economic, environmental and physical dimensions in establishing and promoting social interactions of citizens, and to answer this question: Are sidewalks of urban spaces effective in establishing social communications?

\section{Research methodology}

The present study aimed to examine the functional role of sidewalks in promoting social interactions of citizens. The present study was descriptive-analytic correlational with a survey method. The statistical population included residents of Imamzadeh Hasan (PBUH) neighborhood. Sample size based on Morgan table was 384 people and sampling method was simple random sampling. Data collection tool was a researcher-made questionnaire in the form of survey and organized interview. The data, after being collected, have been coded and entered into SPSS software and descriptive statistics have been extracted. Then, using LISREL software and using measurement models, accuracy of the measurement of the structures by the relevant indicators was investigated. In this section, using second phase confirmatory factor analysis, it was determined that the questions designed in each structure can really measure the considered structure. In other words, validity of the considered questions and indicators was examined and confirmed. Then, using structural equation modeling or confirmatory path analysis, the relationships between latent variables of the study were examined (hypothesis testing and examination of theoretical model of research).

\section{Recognizing the studied area}

District 17 of Tehran municipality with a population of about 260,000 people and an area of 822.09 hectares which accounts for about 1.1 percent of Tehran's metropolis area, as one of the 22 districts of Tehran that has urban function was recognized as the studied area. The mentioned region has the highest gross population density level among other districts of Tehran.

\section{Aminolmolk Street}

Aminolmolk bags and shoes market which ends to Qazvin Street and Shamshiri Square from north, and ends to GhaleMorghi from east, and ends to Yaftabad from west, with its trans-regional function, has a positive role and effect on economic structure of the region and indirectly affects economic landscape of the region. In the meantime, the existence of Imamzadeh Hasan shrine in this area is prominent, and almost all sides of it in the main street are dedicated to commercial-workhouse uses, and interference of various uses is evident there. Altogether, these two commercial and religious centers have turned Aminolmolk Street into one of the main elements of the region's structure.

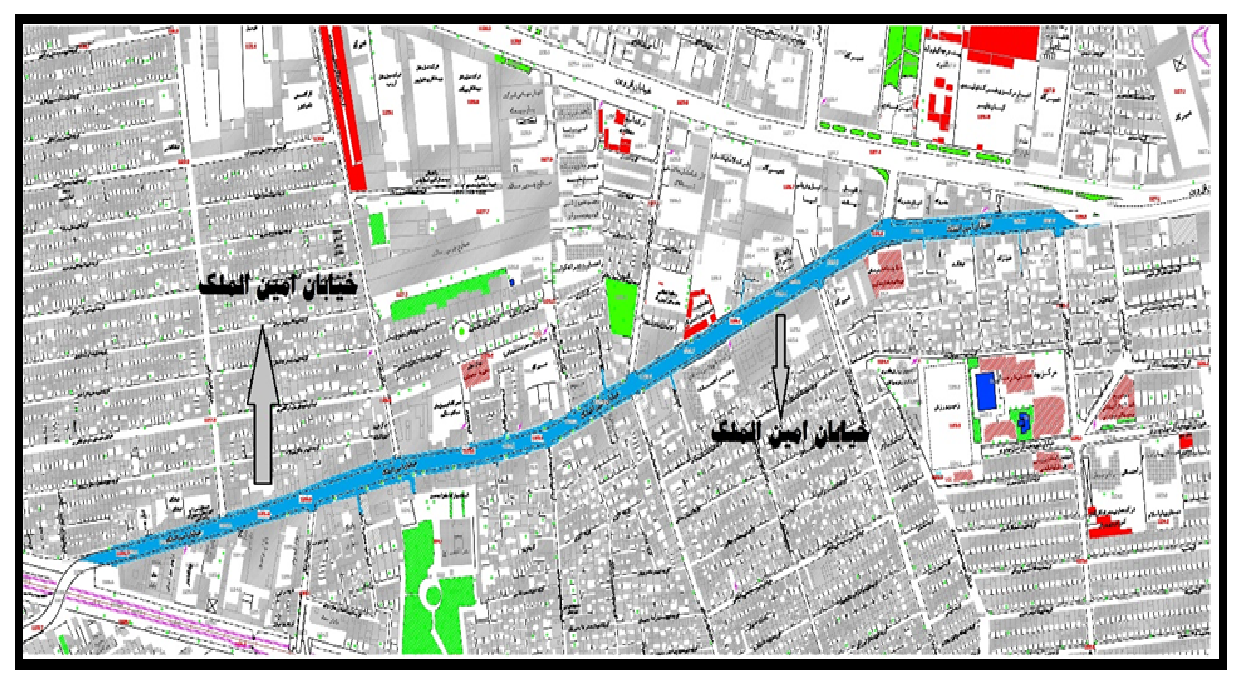

Map 1. Studied area 
The main street in the neighborhood known as Imamzadeh Hasan (PBUH) is called Aminolmolk Street and the density of shopping centers in Aminolmolk Street is at a far distance from Qopan two-way to before YaftabadBridge, in which the furniture market is located after passing this bridge. This street, due to the density of shopping centers and presence of shrine of Imamzadeh Hasan (PBUH), son of Imam Hasan Mojtaba (PBUH), and accumulation of the existing street markets, and in Tasooah and Ashura days due to holding of religious ceremonies, has a lot of overcrowding.

\section{Definition of concepts, views and theoretical foundations}

\subsection{Sidewalk}

Pedestrian-orientation is one of the ways that can be effective in civil revival of urban centers, and through increasing the ground for the presence of citizens in collective places, it increases interactions and social solidarity. In fact, pedestrian areas are parts of urban space that, due to having some special capacities in all or some hours of the day, movement of vehicles is decreased there or they are fully allocated to pedestrian movement (Cratan, 2008, p. 81). In other words, sidewalks are passageways with the highest level of social role in which pedestrians have full dominance, and motor vehicles are only used in order to serve the current life in the passageway (Pakzad, 2006).

\subsection{Social interactions}

Social interaction means creating a relationship between two or more people that leads to a reaction between them, and this type of reaction is known to both parties. Therefore, meaningless relationships do not fall within this definition. Of course, there are other definitions for social interactions, too. For example, social interaction and communication can be a physical issue, a look, a conversation, and a relationship between individuals, which itself requires the definition of proportional events and activities and thus, role playing of people in the space and their membership in social groups and networks (Daneshpour and Charkhchian, 2007: 22). Different people tend to different levels of social interaction. The definition of the desired level of interaction is subjectively obtained from people's statements and objectively from normative positioning toward a good life. Both have a high value definition and have a social and political orientation (Lang, 2002).

\section{Theories related to pedestrians}

In reviewing the views and theoretical foundations of pedestrianization movement, the first work is the book entitled Pedestrian Design and Planning published in 1971 in the United States. In 1975, the publication of Urban Spaces for Pedestrians played an effective role in the promotion of the debates about the improvement of urban spaces. Two years later, a book titled Just for Pedestrians was published by Brambila and Longo in which the basics of planning, designing and management of non-traffic logic in central regions of cities were discussed. In the last two decades, the literature on planning and designing of pedestrians has become very diverse and broad; however, the approach that has been able to use a strong physical, functional, semantic and environmental perspective as its agenda for creating spaces, is a human approach that has been formed in Europe since the eighties and has had a growing process to this day (Karimi and NeginTaji, 2011: 11). In the following, some of the theories related to pedestrian-orientation model have been introduced:

\subsection{Infill development}

Infill development is the process of development of vacant or less used lands or abandoned parts of the existing cities, towns, or neighborhoods. Effective infill development can be a valuable tool in helping to promote the vitality of community and creating sufficient overall residential densities to support alternative desirable transportation options and a wide range of services and facilities and amenities. Also, it can provide alternative housing options in order to meet diverse needs of residents of the community. Infill development can lead to returning of cultural, social and recreational opportunities to a community. It can provide places for increasing interactions among community's inhabitants, and ultimately, infill development can restore or strengthen economic and social vitality in old urban centers and neighborhoods (Cuomo Olsen, 2012). Infill development, with its emphasis on increasing density, causes less dependence on vehicles and leads to the creation of pedestrian-oriented neighborhoods.

\subsection{Modern urban development}

New urbanism or traditional designing of neighborhood units is one of the most serious approaches to urban planning and design of suburbs of American cities, which has been formed since 1980s and 90s in the $20^{\text {th }}$ century in order to resolve the problem of urban suburbs of large cities and metropolises (Hasani and Roshani, no date: 51). 
One of the most important suggested principles of new urbanism for planning in the existing textures is to pay attention to pedestrian movement and pedestrianization of passageways. New urbanism believes that streets and squares should be safe and attractive for walking and should be designed such that they can provide the comfort of the inhabitants and stimulate them to walk. Therefore, it emphasizes that daily and weekly service uses should be at a 10-minute walking distance from residents (AsgharzadehYazdi, 2010: 52).

\subsection{Smart growth}

The concept of smart growth emerged in 1990s following the issues of growth management that had been used in planning system in the 1970s and 1980s. Smart growth has been emerged as a response to the continuation of problems of dispersed development and its negative outcomes, and it has a lot of different historical references that go back to last decades. Among these, efforts for planning national land use, state growth management laws, and changes in housing planning and so on can be mentioned (Edwards, 2007: 49).

One of the principles of smart growth associated with parks and recreational areas is the concept of walkable neighborhood. In this approach, the neighborhood is designed such that it allows the residents to walk to neighborhood elements that are important to them (schools, church, public services, playgrounds, shopping, and work). The design of the city is such that these services are located within an appropriate walking area from mixed and optional housing uses. Therefore, neighborhood design should be such that walking be safe, accessible, attractive and feasible. Parks and recreational systems are a prerequisite for this philosophy. The paths designed and maintained by the institution of parks and recreational areas may serve as the initial corridor for walkable neighborhoods. Walking paths, in addition to walking and cycling, are also considered as recreational places and also represent the travel path of residents (Kelsey, 2011: 2).

\subsection{Dense city}

Dense city strategy has been proposed as the basic model for sustainable urban design by the European Union. The general concept of density has a long history in urban planning, and its history dates back to concentrated city model (Haught and Hunter, 1994). Interest in dense city policies emerged since the late 1980s and was highlighted in Brundtland's Commission Report as an important issue in order to achieve the goals and use the resources and climatic changes.

One of the benefits of this idea of urban growth is to increase the possibility of walking for people and to encourage living in local communities and thus, better monitoring in line with public security (Chen et al., 2008: 29).

\subsection{The role of pedestrian paths in improving the quality of urban space}

Sidewalks, due to their structure, are of great importance in terms of perception of spatial identity, sense of belonging to the environment and reception of beauty; and by attracting a wide range of social groups towards them, they strengthen the sense of convergence, interaction, and direct encounter of citizens, despite different insights, feelings, demands, and tendencies (Mohammadzadeh, 2005). In the present era, sidewalks as urban spaces in many large cities are abundantly used as a forum for holding exhibitions, social events, festivals, advertisements as well as touristic and promotional brochures (Brambila and Longo, 1977: 27).

\subsection{Factors affecting social interactions in public spaces}

Jane Jacobs, a prominent journalist and expert in urban issues in the book Death and Life of Great American Citieshas emphasized on the role of urban public spaces in the creation of social interactions. According to her, what remains in mind from a city is its public spaces, especially its streets and sidewalks, that increased coming and going and security of sidewalks have a reverse effect on segregation and racial discrimination (Kashani, 2011, quoted from Pakzad).

Therefore, sidewalks should be lively so that they can attract more residents. Also, in her view, in order to keep a street lively, a certain number of pedestrians should be present in its sidewalks, while she does not consider high density alone to be enough for vitality (ibid: 99).

Emphasizing on the presence in public spaces and the necessity of encounters, she states that "as soon as interesting, useful, and meaningful encounters between citizens are reduced to private relationships, the city will die". Also, she considers a certain type of relations to be useful and desirable for social relations in streets and believes that people are not so inclined to make around themselves crowded; in fact, she considers good function of streets to be associated with the unconscious experience of feeling of solidarity among pedestrians (Showay, 1996: 369). Public open spaces have a special importance in collective life of citizens that often have the most potential and actual facilities for the presence of citizens, and also they do not have temporal and size constraints and control (Pakzad, 2005). Public open spaces allow for motivating and free choice among behaviors, movements and later discoveries for a significant number of people and citizens (Lynch, 1972: 108); 
in other words, a regular space that easily adapts itself to the diversity of behaviors and allows for neutralization and inducing of spontaneous actions (ibid: 110). In public spaces, there is the opportunity for some social boundaries to be broken and the occurrence of non-predetermined encounters and people s dealing with each other in a new social environment (ibid: 109). Therefore, the essential condition for a public space to be considered as urban space is that social interaction and encounter occurs in it; so, those soft spaces and hard spaces that are not a ground for social interaction are not called urban spaces (Pakzad, 2010).

\subsection{The impact of urban space function on social interactions}

Recognizing human and how he relates to its environment can be effective in shaping the environment for the establishment of more effective interaction and communication. So, in this process, by examining human as a creature with a social dimension that includes various quantitative and qualitative levels of social interactions, the recognition of behavioral establishments and social relations as well as activities having the potential capacity for social actions and meaningful relationships will be important (Behzadfar and Tahmasebi, 2013).

If we assume a city as being consisted of main and subsidiary constructions, both sectors are effected and evolved by components such as natural and climatic conditions, economic and financial forces, political and administrative forces, and social and cultural forces.

\subsection{Factors affecting social interactions}

How a person is present in a place along with others is a strong factor in the person's decision to stay in it. In this regard, people may even search for places in which, people with characteristics similar to them in terms of class, ethnic group, religion, economic group, life style, education, income, the way of raising children, and race are present. However, while homogeneity of people encourages visits and increased interaction with physical and social places and, as a result, promotes attachment to the place, non-homogeneous social spaces are also an opportunity for people to experience being with each other and having rich and free social interactions (Marcus and Sarkissian, 1986).

Amos Rapoport is one of the most prominent theorists of behavioral sciences who have paid attention to urban issues. Proposing the issue of mutual interaction between man and environment, he denies passive status of human in urban space and considers movement in the environment as the most important factor in recognizing the environment and the mental pattern. Jon Lang has also examined the role of behavioral sciences in environmental design. In his work titled Creating Architectural Theory, he explored how people perceive space and the environmental factors affecting this; and he considered people's perceptions of the environment as a kind of mental schema that shapes his behaviors and activities in public area of city (Kashanijou, 2010: 103104).

\section{Results of the research}

\subsection{Descriptive results}

According to the research results, 256 (65.8\%) of the sample members were male and 133 (34.2\%) were female. 53 members of the sample were in the age group of 15 to 24 years; 110 people (28.3\%) were in the age group of 25 to 34 years; 104 people (26.7\%) were in the age group of 35 to 44 years; 106 people (27.2\%) were in the age group of 45-54 years; and 16 people (4.1\%) were in the age group above 55 years. The number of people with high school degree was 64 (16.5\%); associate degree was 110 (28.3\%); bachelor's degree was 109 (28\%); master's degree was 50 (12.9\%) and PhDwas 56 (14.4\%).

\subsection{Analytical results}

\section{Confirmatory factor analysis of sidewalk function}

In this section, the results of confirmatory factor analysis of the research variables have been presented. Given the standardized coefficients` measurement model, it can be concluded that there was a significant correlation between the relevant latent variables and their corresponding indexes. Standardized coefficients, in fact, represent the path or standardized factor loads between factors and indexes. 


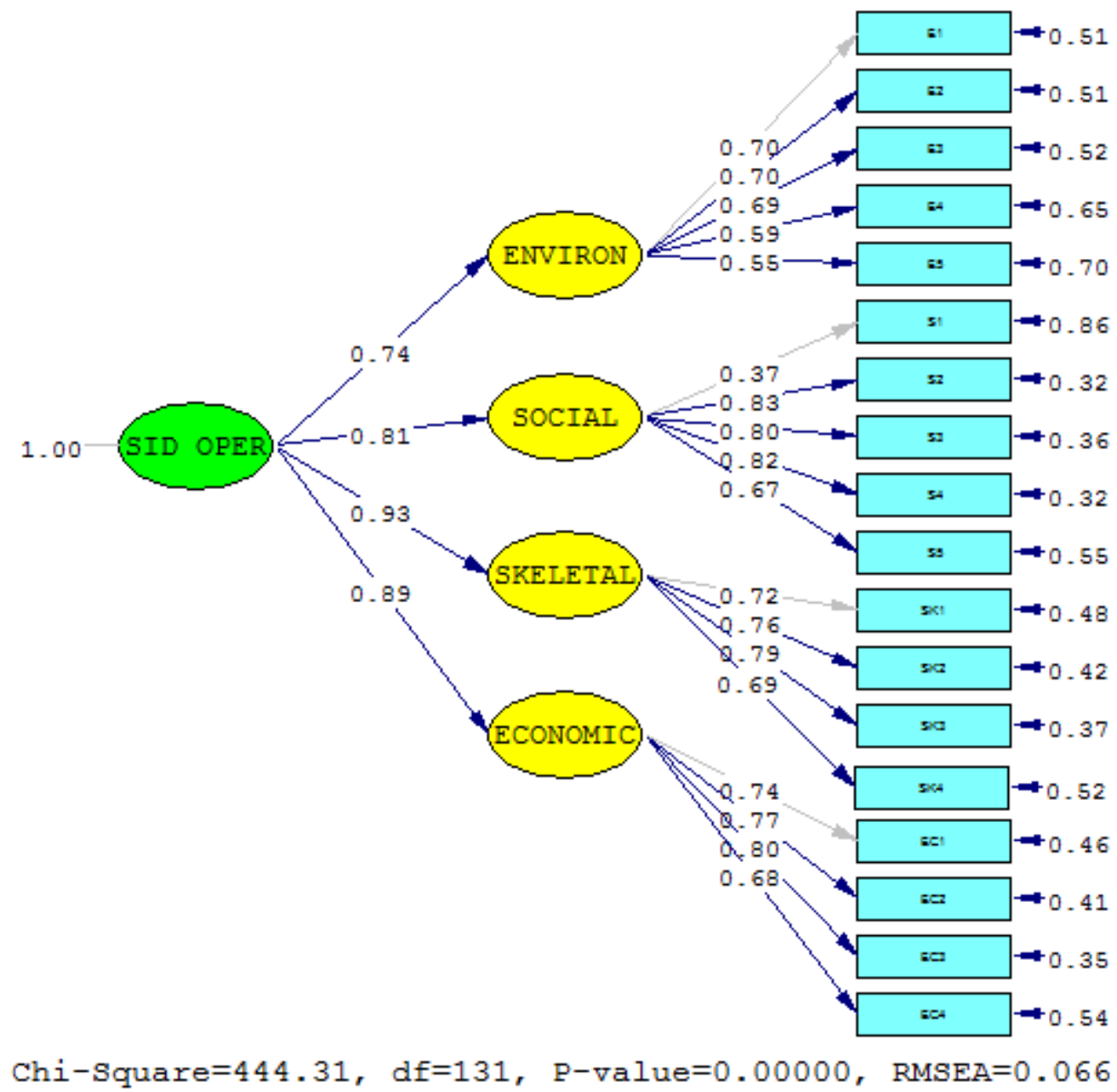

Figure 1. Standard estimation model based on dual correlation coefficients of the questionnaire's structures

Significance numbers model is presented in order to know whether the relationship between structure and dimension and the relationship between dimension and index are significant or no. In this study, all significance numbers of the model parameters were larger than 1.96. Therefore, the validity of measurement structures of the related variables was confirmed at a significance level of 0.05 . 


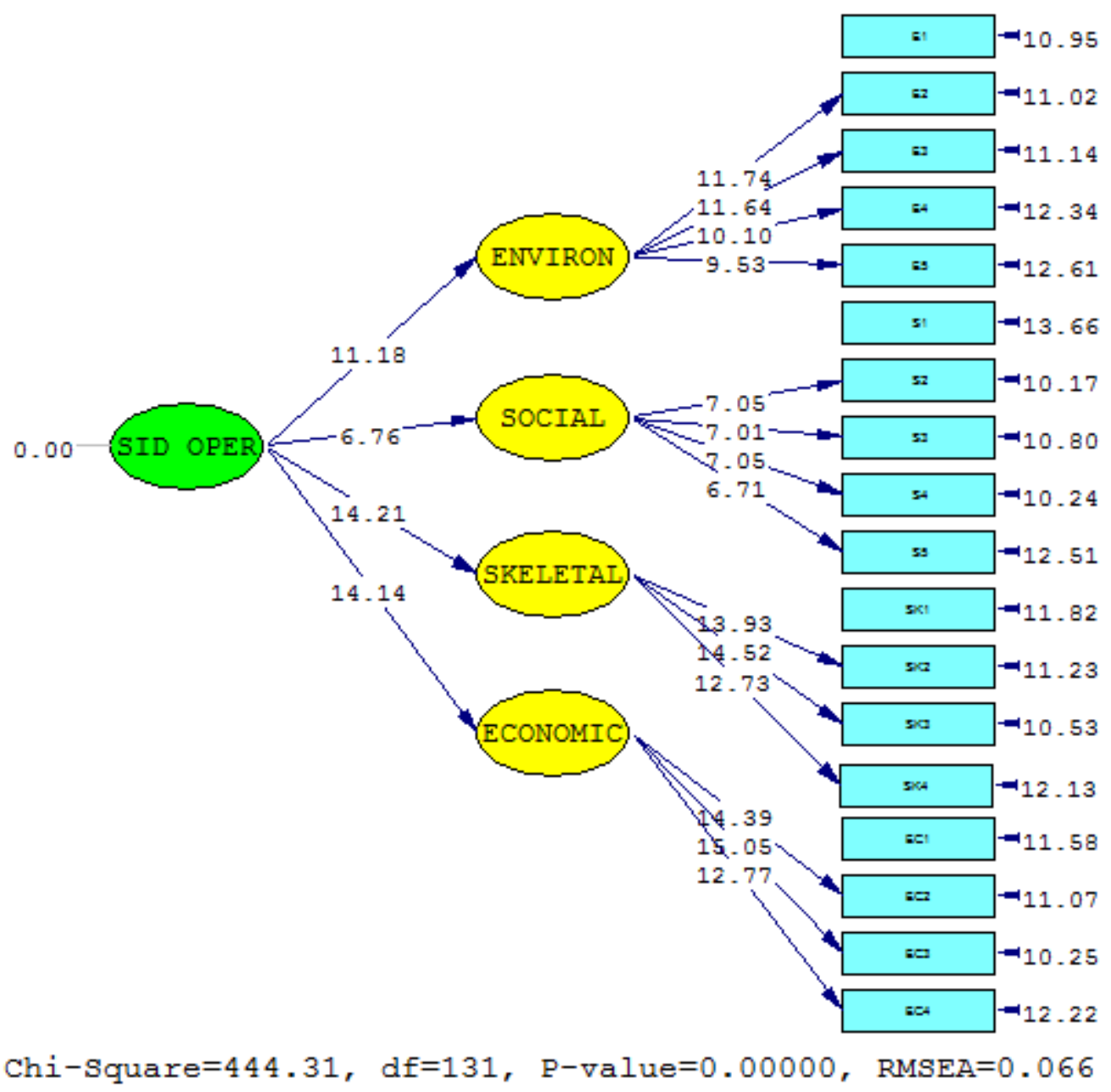

Figure 2. Significance numbers` model (T-Value) of the questionnaire’s structures

\section{Confirmatory path analysis}

In order to test conceptual model of research and the hypotheses, structural equation modeling has been used.

Main hypothesis: Sidewalks play an effective role in promoting social interactions in urban neighborhoods.

First sub-hypothesis: Sidewalks play an effective role in promoting social interactions in urban neighborhoods in terms of social dimension.

Second sub-hypothesis: Sidewalks play an effective role in promoting social interactions in urban neighborhoods in terms of economic dimension.

Third sub-hypothesis: Sidewalks play an effective role in promoting social interactions in urban neighborhoods in terms of physical dimension.

Fourth sub-hypothesis: Sidewalks play an effective role in promoting social interactions in urban neighborhoods in terms of environmental dimension. 


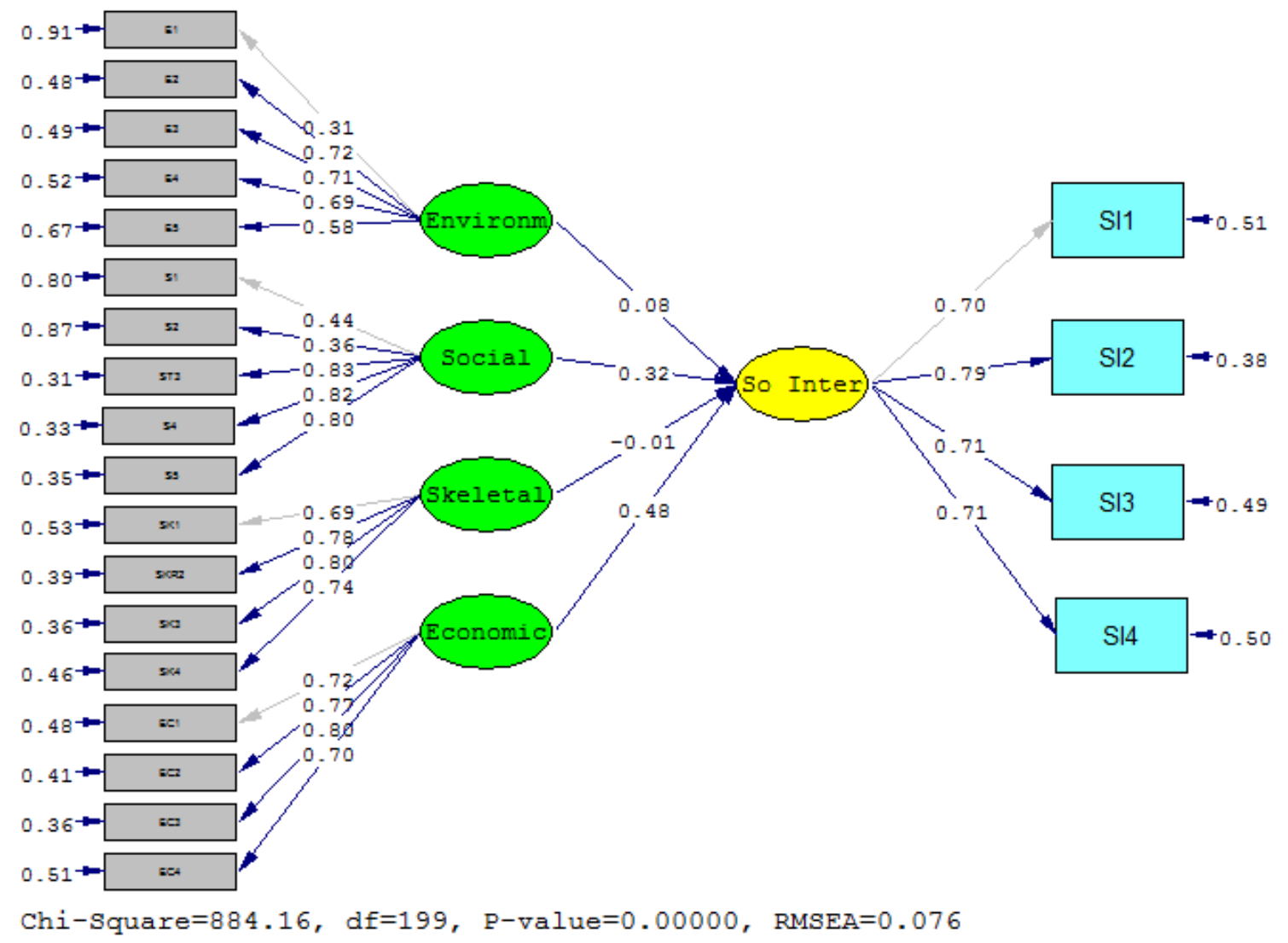

Figure 3. Standard estimation model based on binary correlation coefficients of the conceptual model

Given the standardized coefficients` measurement model, it can be concluded that there was a positive and significant correlation between the relevant latent variables and their corresponding indexes. Standardized coefficients, in fact, represent the path or standardized factor loads between factors and indexes. As the model shows, the questions had a good explanation power. 


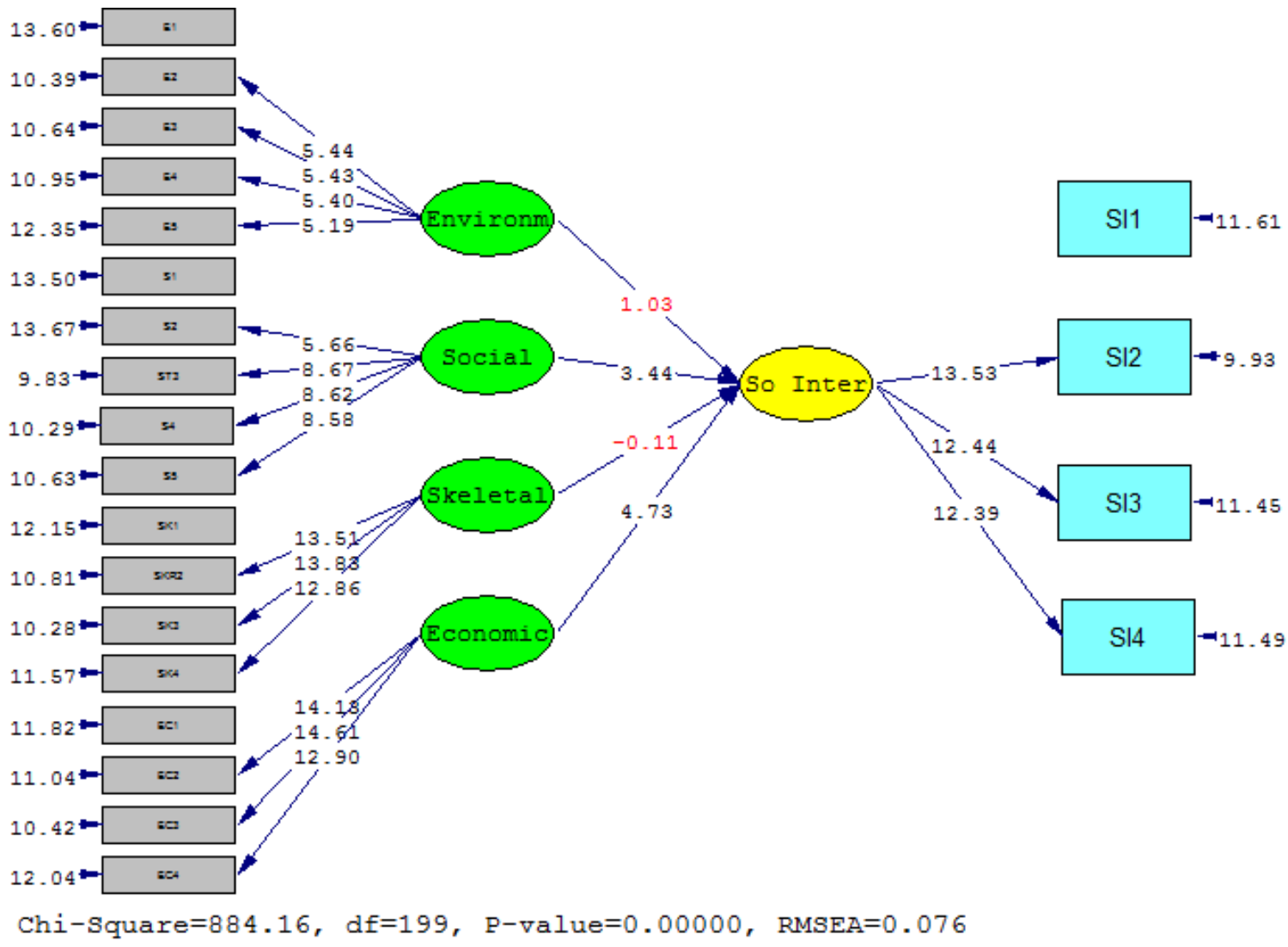

Figure 4. Significance numbers` model (T-Value) of the conceptual model of research

Significance numbers model (T-value) shows the significance of each of the parameters, and if its value be greater than the absolute value of 1.96, parameters of the model would be significant and the hypotheses of the related variable would be confirmed. In the present study, T-value of social (3.44) and economic (4.73) variables were significant and therefore, the hypotheses related to these variables (first and second hypotheses) were confirmed and the third and fourth hypotheses were rejected.

\section{Conclusion}

This study has been conducted aiming to examine the functional role of sidewalks in promoting social interactions in Imamzadeh Hasan (PBUH) neighborhood and Aminolmolk Street in Tehran. Undoubtedly, old neighborhoods with trans-regional identity and function, as one of the areas of urban spaces, have the potential to create suitable ground for the formation of social interactions. Neighborhood is physical manifestation of community and its boundaries are the manifestation of territories. Attention to social dimension of neighborhood, social and non-physical territories, and the creation of physical elements that can provide the boundaries of social territory as much as possible, can lead to more organization of mutual interactions and social interactions. Restoration of neighborhood centers that have identity, is one of the social needs of a city. In order to attract people to social spaces, a neighborhood should have security indexes, accessibility, monitoring, and holding of religious-national and ancient ceremonies with collective nature in public spaces along with the construction of cultural centers, cafes and internet cafes. One of the public spaces of neighborhoods is sidewalks. Sidewalks as a place of citizens' passage are one of the most important urban spaces for establishing and promoting social interactions. Sidewalks of Aminolmolk Street, located in a traditional neighborhood, are the scene of regional and sometimes trans-regional functions, and although they do not have an ideal and sustainable environmental and physical quality, they have good performance in terms of economic and social functions and they provide the basis for sustainable social actions among residents and visitors. 


\section{References}

[1] Bentley et al. (2003); Responsive Environments; Translated by M. Behzadfar, Tehran: Publications of Iran University of Science and Technology.

[2] Behzadfar, M., and Tahmasebi, A. (2013); Identification and Evaluation of Components Affecting Social Interactions Strengthening and Developing Citizen Relationships in Urban Streets: Case Study: Sanandaj, Nazar Garden.

[3] Pakzad, J. (2006); Theoretical Foundations and Urban Design Process; Tehran: Shahidi.

[4] Pakzad, J. (2005); Guide for Designing Urban Spaces in Iran; Tehran: Ministry of Housing and Urban Development.

[5] Pakzad, J. (2010); Procedure of Thoughts in Urban Development (Vol. 1-3), Tehran: Armanshahr Publications.

[6] Rasouli, Sara, and RahimdokhtKhorram, Mira (2009); Creating Favorable Urban Landscape in Pedestrian Paths; Armanshahr, No. 3, pp. 103-112.

[7] Daneshpour, S., and Charkhchian, M. (2007, Spring and Summer); Public Spaces and Factors Affecting Collective Life; Bagh-e-Nazar Journal, pp. 19-28.

[8] Showay, F. (1996); Urban Development, Facts and Imaginations; Translated by S. Habibi, Tehran: Tehran University Press.

[9] KashaniJou, Kh (2010, Spring and Summer); Recognizing Theoretical Approaches to Urban Public Spaces; (6), Journal of Hoviat-eshahr, Fourth Year, pp. 95-106.

[10] Karimi, Mehrdad and NeginTaji, Samad (2012); Designing of Sidewalks in Tehran, with an Emphasis on Social Needs; DaneshShahr, No. 123.

[11] Lang, J. (2004); Creation of Architectural Theory; Translated by M. Ahmadinejad, Tehran: Tehran University.

[12] Mohammadzadeh, R. (2005); Modernity and Urban Development, Case Study of Old Texture of Tabriz City; Tabriz: PhD thesis, Faculty of Humanities and Social Sciences.

[13] Madanipour, A. (2008); Public and Private Spaces of City; Tehran, Urban Processing and Planning Company of Tehran Municipality.

[14] Alexander, C. (1987). A New Theory of Urban Design. New York: Oxford University Press.

[15] Bacon, E. (1974). Design of Cities. New York: The Viking Press.

[16] Brambila, R., \& Longo, G. (1977). For Pedestrians Only: Planning and Management of Traffic Free Zones. New York: Whitney library of Design.

[17] Cratan, F. (2008). Side Walk in Urban Planning. London.

[18] Gehl, J. (1987). life Between Building: Using Public Space. New York: Van nor strand Reinhold.

[19] Giddens, A. (1990). Sociology. New York: Polity Press.

[20] Jacobs, J. (1961). The Death and Life Great American Cities. New York: The Failure of Town Planning.

[21] Lynch, K. (1972). The Image of the City. Cambridge: Ma: The MIT Pres.

[22] Marcus, C., \&Sarkissian, W. (1986). Housing as if People Mattered. Berkeley: University of California Press.

[23] Rapoport, A. (1977). Human Aspects of Urban Form. New York: Pergamon Press.

[24] Trancik, R. (1986). Finding Lost Space. New York:: Van Nostrand Reinhold. 